\title{
Release profile of ibuprofen in $\beta$-cyclodextrin complexes from two different solid dosage forms
}

\author{
P.J. Salústio ${ }^{a^{a}}$, G. Feio ${ }^{\text {b.c }}$, J.L. Figueirinhas ${ }^{\mathrm{c}}$, H.M. Cabral-Marques ${ }^{\mathrm{a}}$, P.C. Costa ${ }^{\mathrm{d}}$, J.F. Pinto ${ }^{\mathrm{a}}$
}

${ }^{a}$ Research Institute for Medicines and Pharmaceutical Sciences (iMed.UL), Faculty of Pharmacy, University of Lisbon. Av. Prof. Gama Pinto, 1649-003 Lisbon, Portugal

${ }^{b}$ Departamento de Ciências de Materiais, Faculdade de Ciências e Tecnologia da Universidade Nova de Lisboa, P-2829-516 Caparica, Portugal

${ }^{c}$ CFMC/UL, P-1649-001 Lisboa, Portugal

${ }^{d}$ Laboratório de Tecnologia Farmacêutica, Departamento de Ciências do Medicamento, Faculdade de Farmácia da Universidade do Porto, Rua Aníbal Cunha 164, P-4050-047 Porto, Portugal

Running head: Release of ibuprofen by complexation with $\beta$-cyclodextrin

* Corresponding author.

$i$-MED, Faculdade de Farmácia da Universidade de Lisboa

Av. Prof. Gama Pinto

1649-003 Lisboa

E-mail: pjsalustio@ff.ul.pt

Tel.: +351217946411

Fax: +351 217946470 


\begin{abstract}
The objective of this work was to develop solid dosage forms using powders containing inclusion complexes (ibuprofen with $\beta$-cyclodextrin) which were used to produce tablets (direct compression without additional excipients) and pellets (extrusion/spheronization) from wet mass containing $40 \%$ (w/w) of microcrystalline cellulose. The pellets also demonstrated that during preparation of the wet mass, the inclusion process occurred in a same yield that when pre-complexation was used. The particles characteristics were evaluated after being obtained through different complexation methods. The results showed that the tensile strength and profile dissolution were as expected for both dosage forms. Tablets containing inclusion complexes showed higher solubility when compared with a reference formulation and with two commercial formulations. The ibuprofen released from the two pellets formulations didn't show relevant differences between them. The drug released was analyzed considering different dissolution parameters. The advantages of these new methodologies can be summarized as: (a) tablets were produced at a lower cost for the total process; and (b) in the pellet's preparation there was no need of the previous complexation method resulting in a decrease in time and energy required.
\end{abstract}

Keywords: $\beta$-cyclodextrin, dissolution, ibuprofen, pellet, tablet 


\section{Introduction}

Drugs to be incorporated into solid dosage forms should present high water solubility and high permeability throughout the gastrointestinal mucosa, like the ones belonging to Class I (Biopharmaceutical Classification System, BCS) [1]. Consequently all drugs that do not present such characteristics have to be transformed (chemically or physically) to improve solubility and/or permeability. For Class II, the drug's (e.g. Ibuprofen - IB) [2] solubility in aqueous media affects its release and thus the bioavailability may also be affected negatively. Some technologies used to increase drug solubility can lead to changes in their particles characteristics and thus influence the processability, stability and bioavailability of the solid dosage forms made from them.

The complexation of a drug with cyclodextrins (CDs) is a commonly used method to improve its solubility [3,4]. Cyclodextrins are cyclic oligosaccharides consisting of six, seven or eight glucose molecules looking like a truncated cone or torus. The torus presents an external hydrophilic surface that facilitates an easy dissolution in water, whereas its cavity is far less polar allowing the interaction with the non-polar parts or the whole molecules of approximately its size, leading to the formation of the inclusion complexes [3,4].

The literature describes different techniques to form complexes with cyclodextrins, all leading to an improvement in the drugs' solubility, when compared with pure drugs' solubility [3-7]. Several studies performed by other authors showed the feasibility of the various processes of complexation in the inclusion complex formation between IB and $\beta \mathrm{CD}$. The different results corroborated the inclusion complex formation and showed that the particles characteristics were dependent of the complexation methods [8-13]. These characteristics (shape, size distribution, crystalline or amorphous state) can influence the processing of the solid dosage form and subsequently the release of the drug in water. The inclusion complexes obtained by different technologies can be regarded as raw materials in the preparation of the solid dosage forms, and their compactibility, extrudability and dissolution profiles are dependent on the characteristics of both the inclusion complex particles and the dosage form $[7,8]$.

The aim of this study was to analyze the possibility of producing tablets from powders containing inclusion complexes, without using additional excipients, and the ability of forming inclusion complexes (IB $\beta \mathrm{CD}$ ) during wetting of the extrusion mass in the pellets' production. The particles' characteristics were evaluated after being obtained through different complexation methods. Moreover, for both tablets the IB released was compared in between them and also with the ones observed with commercial formulations. The IB released was also compared for both pellets formulations.

\section{Materials and methods}

\subsection{Materials}

The model drug chosen for this study was ( \pm )-Ibuprofen, (racemic $\alpha$-methyl-4-[2methylpropyl] benzene acetic acid, IB), a practically insoluble in water drug (supplied by Capsifar, Portugal). For the preparation of the solid dosage forms $\beta$-cyclodextrin (Wacker, Germany, $\beta \mathrm{CD}$ ), lactose (Granulac 200 Meggle, Germany, LAC) and microcrystalline cellulose (Avicel PH 101, FMC Biopolimer, Ireland, MCC) were used. A generic and a brand name, non-coated commercially available tablets with $200 \mathrm{mg}$ IB were used for comparison, respectively Com 1 (mean mass \pm standard deviation: $269.0 \pm 3.31 \mathrm{mg}$ ) and Com2 (366.9 $\pm 8.37 \mathrm{mg})$. Hydrochloric acid solution (pH 1.0) was used as dissolution medium [14]. 


\subsection{Methods}

\subsubsection{Preparation of the inclusion complexes}

The preparation of the inclusion complexes (IB $\beta$ CD K70 and IB $\beta C D$ FD) was described in a previous study [5] (Table 1). Briefly, IB and CD were mixed in a 1:1 stoichiometric proportion (molar ratio) and water was added: either $70 \% \mathrm{w} / \mathrm{w}$ (K70), i.e., kneading or in such a quantity to produce a suspension/solution $\left(1.63 \times 10^{-2} \mathrm{M}\right.$ at $25^{\circ} \mathrm{C}$ for $\left.\beta \mathrm{CD}\right)$. The kneaded mass was dried in the preparation mortar whereas the suspension/solution was dried by freeze-drying (Christ Alpha 1-4, B. Braun Biotech International, Germany: the samples were previously frozen at $-20{ }^{\circ} \mathrm{C}$ and then dried at 4.5-7.0 $\mu$ bar for 48 hours). The powders obtained were sieved (Retsch, Germany) and, if required, milled to produce particles with less than $250 \mu \mathrm{m}$ considered for tabletting and pelletization.

\section{Table 1}

Composition of powder mixtures with ibuprofen.

\begin{tabular}{lll}
\hline \multirow{2}{*}{ Ibuprofen } & Preparation method & Water removal \\
\cline { 2 - 3 } IBLAC & powder mix & not applicable \\
IB $\beta$ CD K70 & kneading with 70\% of water & paste formation \\
IB $\beta$ CD FD & suspension/solution & freeze-drying \\
\hline
\end{tabular}

\subsubsection{Preparation of the reference mixture}

A mixture containing IB with LAC was produced in a tumble mixer for 10 min (Fisher-Kendall Scientific Co, USA) (Table 1).

\subsubsection{Characterization of the inclusion complexes and reference mixture}

The mixtures IB $\beta$ CD K70 and IB $\beta$ CD FD were characterized in a previous study [5] by optical microscopy $(O M)$, differential scanning calorimetry $(D S C)$, ultraviolet spectroscopy $(U V)$, infrared with Fourier Transformer $(F T I R)$, nuclear magnetic resonance (NMR) and X-ray diffraction $(X D P R)$ in order to prove the existence of inclusion complexes and their complexation stoichiometry [10]. In this study the raw materials (IB, $\beta \mathrm{CD}$ and LAC) and powder mixtures (IBLAC, IB $\beta$ CD K70 and IB $\beta$ CD FD) were observed by electron microscope (JEOL-JSM-S200LV Scanning Microscope, JOEL-JFC-1200 Fine Coater, USA) on a magnification 100, 350 and 1,500 $X$. The bulk and tapped densities were assessed by measuring cylinder $\left(50 \mathrm{~cm}^{3}\right)$ [14]. The parameter Carr index (ICr) [15] was determined using the following equation: 


$$
I C_{r}=\frac{D_{f}-D_{0}}{D_{f}} \times 100
$$

where, $D_{0}$ is the initial bulk density and $D_{f}$ is the tap bulk density. The true density was determined by helium pycnometry (AccuPyc 1330, Micromeritics, USA). The flow properties of the powders were examined with an Erweka GT Granule tester (Erweka, Germany): powders were poured into a funnel and then allowed to pass through a nozzle of $15 \mathrm{~mm}$ diameter onto plate for $10 \mathrm{~s}$. The angle of repose was calculated as the angle of the powder's cone to the plate.

\subsubsection{Preparation of tablets and pellets}

Tablets (1300 mg powder containing $200 \mathrm{mg}$ IB) were prepared for all mixtures shown in Table 1 in an universal testing machine (Lloyd Instruments LR 50K, UK) with a $50 \mathrm{kN}$ load cell allowing the recording of the force and displacement of $13 \mathrm{~mm}$ diameter punches. The compaction force applied was $10.0 \mathrm{kN}$ with an upper punch speed of $10 \mathrm{~mm} / \mathrm{min}$. This load was chosen as the maxim limit to influence the volume reduction behavior, particle size and compaction load on bonding mechanisms. The chosen dose corresponds to the lowest adult's commercial dosage. This small dose still allows the production of tablets with appropriate dimensions.

Pellets with and without inclusion complexes were produced by extrusion/spheronization [16-18] where the microcrystalline cellulose (MCC) was used as extrusion/spheronization excipient. The powders for the preparation of the pellets were mixed in the ratio (w/w) of 40 parts of the MCC and 60 parts of the IB and $\beta \mathrm{CD}(1: 1$ molar ratio) (PL) for 5 min in a planetary mixer (Kenwood Chief, UK). Another mixture (40:60) was made of IB $\beta$ CD K70 instead individual weighing of the IB and $\beta \mathrm{CD}$ and was designed PL K70. For the two formulations the appropriate quantity of water $(55 \% \mathrm{w} / \mathrm{w})$, was slowly added to the powders and kneaded for $10 \mathrm{~min}$. Approximately $100 \mathrm{~g}$ of each wet mass was packed manually into the barrel of a ram extruder and fit with a $1 \mathrm{~mm}$ diameter die. The ram extruder was attached to an universal testing machine (Lloyd Instruments LR 50K, UK) operated at $100 \mathrm{~mm} / \mathrm{min}$. Spheronization of extrudates was carried out in a spheronizer fit with a crosshatch plate (GB Caleva, Model 230, UK) rotating at $1000 \mathrm{rpm}$ for $20 \mathrm{~min}$. The pellets were dried in a fluidized bed (Aeromatic-Fielder AG, Switzerland) at $45^{\circ} \mathrm{C}$ for $30 \mathrm{~min}$. The $1.0-1.4 \mathrm{~mm}$ fractions were used in the study.

\subsubsection{Tablets and pellets crushing and tensile strength}

The crushing strength (CT5, Engineering systems, UK) of both tablets and pellets was found by the application of maximum loads of $490 \mathrm{~N}$ and $49 \mathrm{~N}$, at a $6.9 \mathrm{~mm} / \mathrm{min}$ displacement, respectively. The tensile strengths for tablets and pellets were calculated from the following equations $[19,20]$ :

$$
\sigma_{t}=\frac{2 F}{\pi D h}
$$




$$
\sigma_{t}=\frac{0.4 F}{\pi r^{2}}
$$

where, $F$ is the force applied to the sample, $D$ and $h$ the diameter and height of the tablet, respectively and $r$ the pellet radius.

\subsubsection{Dissolution studies}

In vitro drug release was monitored taking into consideration the dissolution test described in the European Pharmacopoeia [14], paddle method (50 rpm) using a dissolution apparatus (Sotax model AT7, Switzerland) containing $1000 \mathrm{ml}$ of hydrochloric acid solution $\mathrm{pH}$ 1.0. The $\mathrm{pH}$ used corresponds to drastic conditions for IB solubility to allow comparison between references and processed powders. The IB released was quantified in a UV-Vis spectrophotometer (U-200, Hitachi, Japan) set at $221 \mathrm{~nm}(\beta \mathrm{CD}$ has no significant absorption [21]), at predetermined times (10, $20,30,40,60,90,120,180$ and 1440 min - the last value was chosen to allow the comparison of the total IB released, between dosages forms with inclusion complexes and references). The cumulative fraction of the drug released was calculated from the total amount of IB and plotted as a function of time $(\mathrm{n}=3)$. Pellets and tablets, both commercial and produced as described, containing $200 \mathrm{mg}$ IB were weighted and placed in each dissolution vessel (using no sink conditions).

The data from the release of IB was analyzed using different dissolution parameters, namely, comparison of the amounts released at determined times $\left(M_{t m i n}\right)$, the efficiency of dissolution $(D E)$ and the similarity factor $\left(f_{2}\right)$ [22]. Dissolution data, at some time points $\left(M_{\text {tmin }}\right)$ (30, 60 and $180 \mathrm{~min}$ ) was compared statistically by ANOVA and by post-hoc Tukey test (SPSS Statistics 17.0, SPSS Inc., Chicago, USA), at $\alpha=0.05$ significance level.

\section{Results and Discussion}

\subsection{Powders and reference mixtures}

The particles shape is a parameter that can influence some pharmaceutical properties of the raw-materials as well as the processed products (flux, rearrangement in the die). The number and strength of the bounds created between particles during formulation processes (granulation, compactation) is also related with the particles' shape. These factors determine the quality of the solid dosage forms and consequently the drug release behavior in water.

The observation of particles by electronic microscopy has shown differences between particles (Fig. 1). IB particles presented a rod shaped form with smooth surfaces (Fig. 1, top), like $\beta C D$ presenting a cubic shape with smooth surfaces (Fig. 1, middle). On the other hand, LAC particles present irregular forms and rough surfaces (Fig. 1, bottom). Fig. 2 shows the particles produced for the reference mixture (Fig. 2, top, IBLAC) which is a mixture of particles of raw materials with different sizes and shapes, as described for IB and LAC (Fig. 1). Particles' shapes and sizes for this reference mixture didn't change after mixing. For IB $\beta C D$ K70 and IB $\beta C D$ FD 
mixtures the complexation methods and their drying processes generated particles with other morphologies, different from the raw materials particles from which they were originated (Fig. 2, middle and bottom). However, some rod shaped particles can still be seen in those mixtures, which correspond to a low amount of pure IB. These observations confirm as previously referred in another study [5], that a different entity (inclusion complex) was formed. IB $\beta$ CD K70 showed rough and cubic particles, whereas IB $\beta$ CD FD showed more elongated particles. It must be pointed out that the sizes and shapes of particles were also affected by the technique considered for the formation of the complex (kneading or suspension/solution), drying (freeze-drying or simple evaporation by exposure to dried air during the kneading process) and grinding. This means that morphology changes might have happened due to complexation but other techniques must prove the formation of the complex, namely NMR, FTIR, XRPD, as described previously [5].

\section{Ibuprofen}
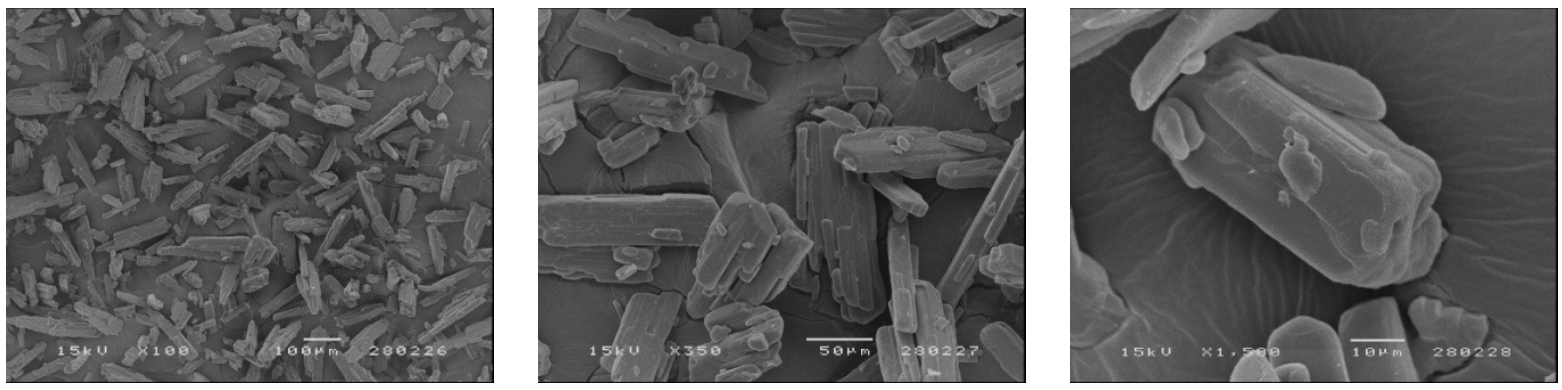

\section{$\beta$-ciclodextrin}
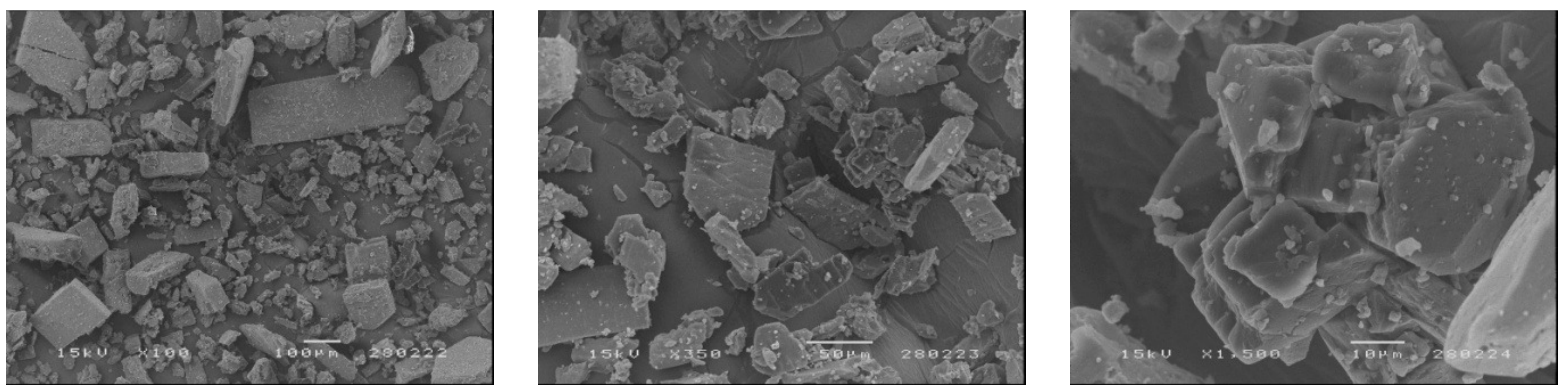

\section{Lactose}

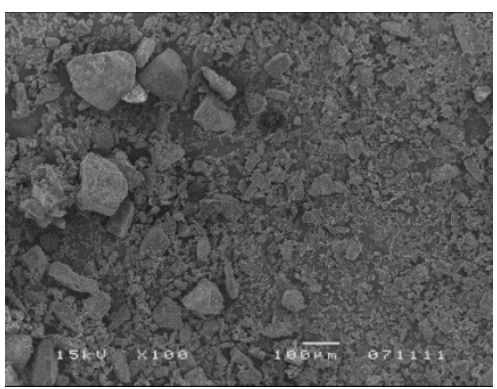

100X $(100 \mu m)$

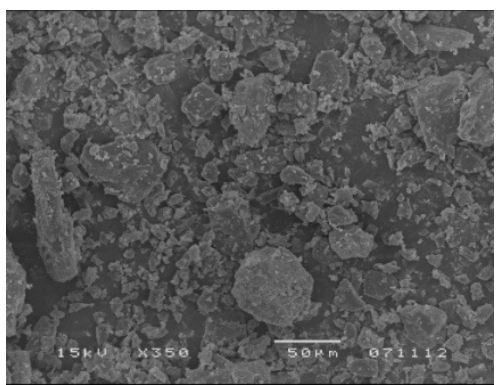

$350 X(50 \mu m)$

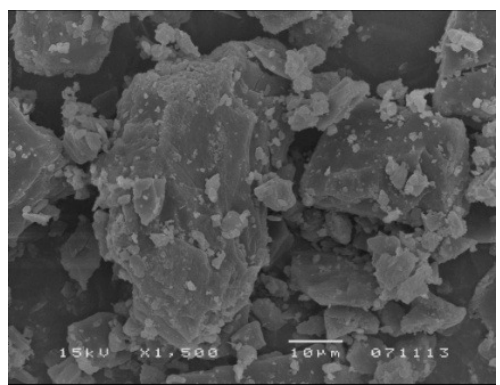

$1500 X(10 \mu m)$

Fig. 1. Scanning electron micrographs of raw-material (IB, $\beta C D$, LAC). 
IBLAC
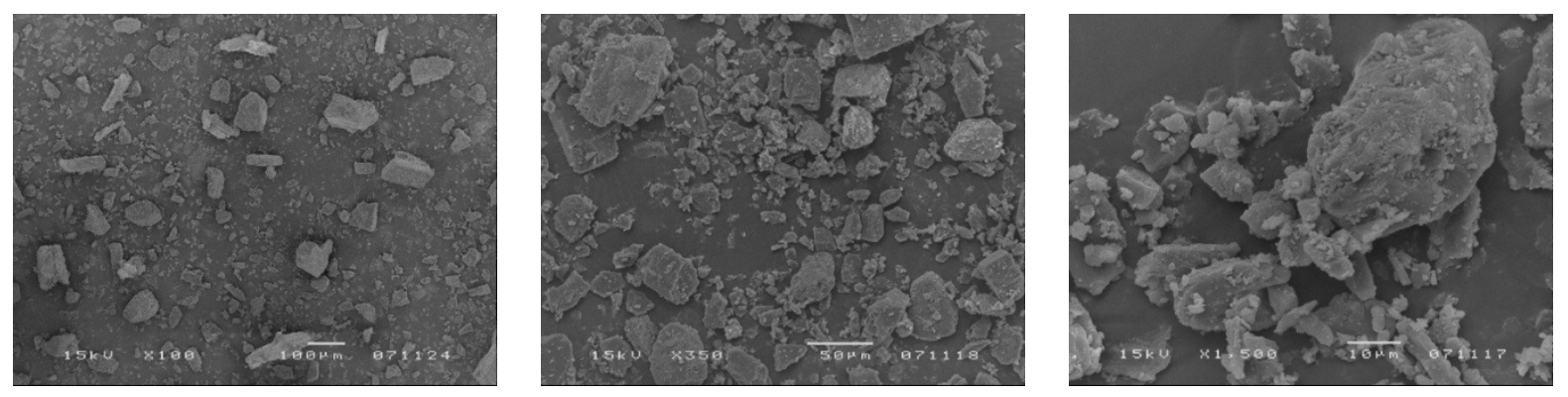

\section{IB $\beta$ CD K70}
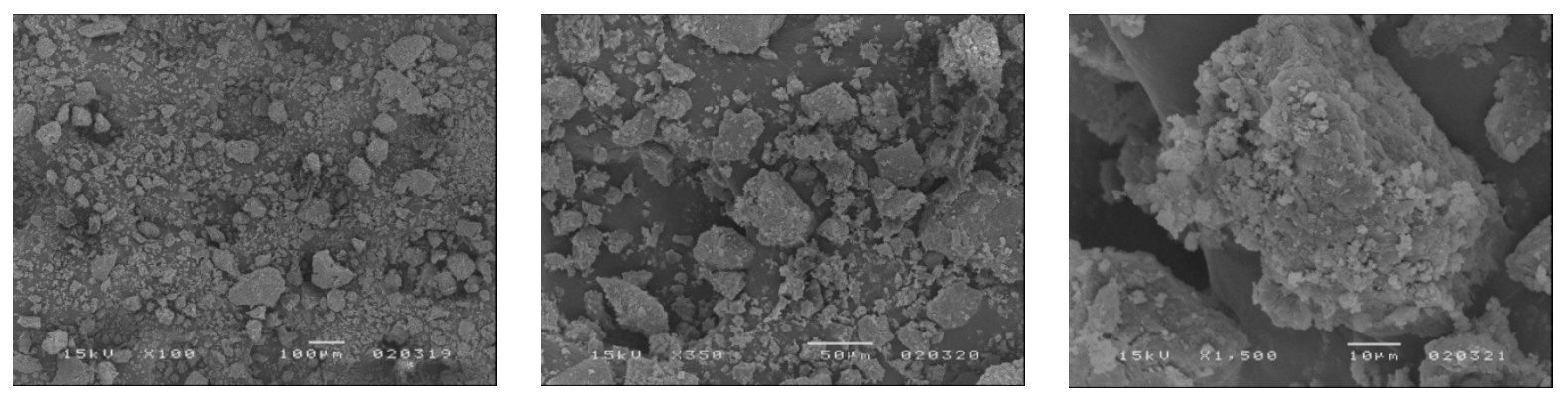

\section{IB $\beta$ CD FD}

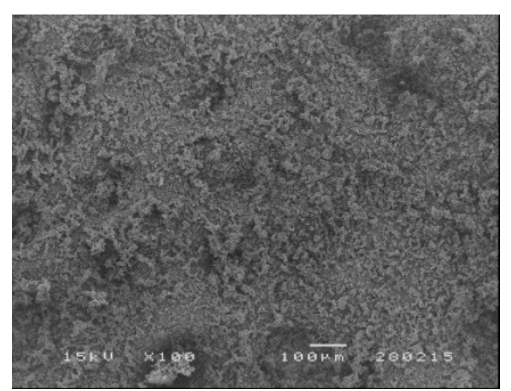

100X $(100 \mu m)$

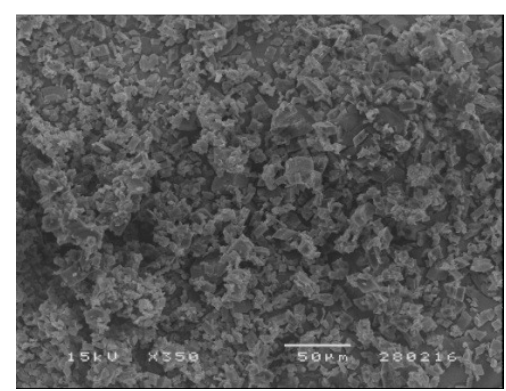

$350 X(50 \mu m)$

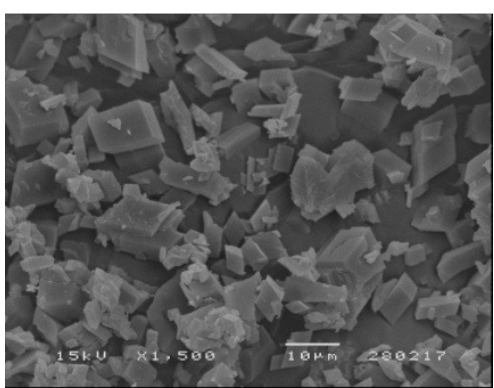

1500X $(10 \mu m)$

Fig. 2. Scanning electron micrographs of reference (IBLAC) and inclusion complexes (IB $\beta C D$ K70, IB $\beta$ CD FD) mixtures.

The apparent and tap densities of the raw materials (Table 2) showed that the IB is the material with higher interparticle porosity [15,23]. The values of $\beta \mathrm{CD}$ are largely in line with those presented in the literature $\left(0.42-0.59\right.$ and $0.74-0.76 \mathrm{~g} / \mathrm{cm}^{3}$ for the apparent and tap densities, respectively [3]. 
Table 2

Results for the bulk, tap and true densities, compressibility index and angle repose of powders ${ }^{\text {a) }}$.

\begin{tabular}{cccccc}
\hline Raw-materials & $\begin{array}{c}D_{0} \\
\left(\mathrm{~g} / \mathrm{cm}^{3}\right)\end{array}$ & $\begin{array}{c}D_{f} \\
\left(\mathrm{~g} / \mathrm{cm}^{3}\right)\end{array}$ & $\begin{array}{c}I C_{r} \\
(\%)\end{array}$ & $\begin{array}{c}\rho \\
\left(\mathrm{g} / \mathrm{cm}^{3}\right)\end{array}$ & $\begin{array}{c}\text { Angle of repose } \\
\left({ }^{\circ}\right)\end{array}$ \\
\cline { 2 - 6 } IB & 0.29 & 0.51 & 43.00 & 1.12 & 57.17 \\
$\beta$ CD & 0.54 & 0.75 & 28.00 & 1.48 & 47.80 \\
LAC & 0.53 & 0.89 & 41.00 & 1.55 & 51.53 \\
Mixtures with IB & & & & & \\
IBLAC & 0.55 & 0.85 & 36.00 & 1.46 & 49.40 \\
IB $\beta$ CD K70 & 0.51 & 0.74 & 31.00 & 1.41 & 49.93 \\
IB $\beta$ CD FD & 0.22 & 0.39 & 44.00 & 1.48 & 58.47 \\
\hline
\end{tabular}

The coefficient of variation was below $1 \%$ for all cases

$D_{0}=$ bulk density

$D_{f}=$ tap density

$I C_{r}=$ compressibility index

$\rho=$ true density

a) results are the mean of 3 measurements $(n=3)$

The powder with a larger interparticle porosity is the one obtained by removal of the water by freeze-drying (IB $\beta C D$ FD). Freeze-drying leads to products with higher porosity and high amorphous content than other processes [3,24]. The densities of the reference mixture (IBLAC) showed values very similar to the original components, i.e., close to the component that existed in larger quantities (LAC). For powders made of inclusion complexes, the apparent densities were variable depending mainly on their ability to flow and ease on the manual filling of the die in the compaction process, as shown by the Carr's index and angle of repose determinations (Table 2). These powders can be regarded as poor flowing materials [15,23,25].

The results for the true densities showed small differences between the IB $\beta \mathrm{CD}$ K70 and $\mathrm{IB} \beta \mathrm{CD}$ FD samples resulting from the complexation methods. For IB $\beta \mathrm{CD}$ FD mixture the measured density (1.48) was higher than the expected density (1.42) [26] resulting in the possible decrease of the intraparticle porosity. The expected density $\left(\mathrm{g} / \mathrm{cm}^{3}\right)$ for the IB $\beta C D$ FD mixture $(1: 1)$ was calculated using the following expression:

$(\%$ drug $\mathrm{x}$ true density of drug $)+(\% \beta \mathrm{CD} \times$ true density of $\beta \mathrm{CD})$

using helium pycnometry (AccuPyc 1330, Micromeritics, USA).

\subsection{Tablets and pellets}

\subsubsection{Compaction profiles}

The compaction profiles of the tablets obtained from compressing each mixture are shown in Fig. 3 reflecting a well known logarithmic relationship between the displacement of the punch and the force applied. Although the profiles were not too different, one can differentiate between both the IBLAC and IB $\beta$ CD K70 and the IB $\beta$ CD FD. The later has shown a smoother increase on the force suggesting that the materials did better accommodate the force applied at early stages of 
compression than the other two. This might have happened as a consequence of a higher porosity between particles (not within particles) that made difficult the repacking of these particles [7,24,2729] and this is reflected by the highest energy of compaction (area under the force versus displacement curve) which was $20.7 \mathrm{~J}$. For other mixtures (IB $\beta$ CD K70 and IBLAC) the values were $12.5 \mathrm{~J}$ and $9.0 \mathrm{~J}$, respectively.

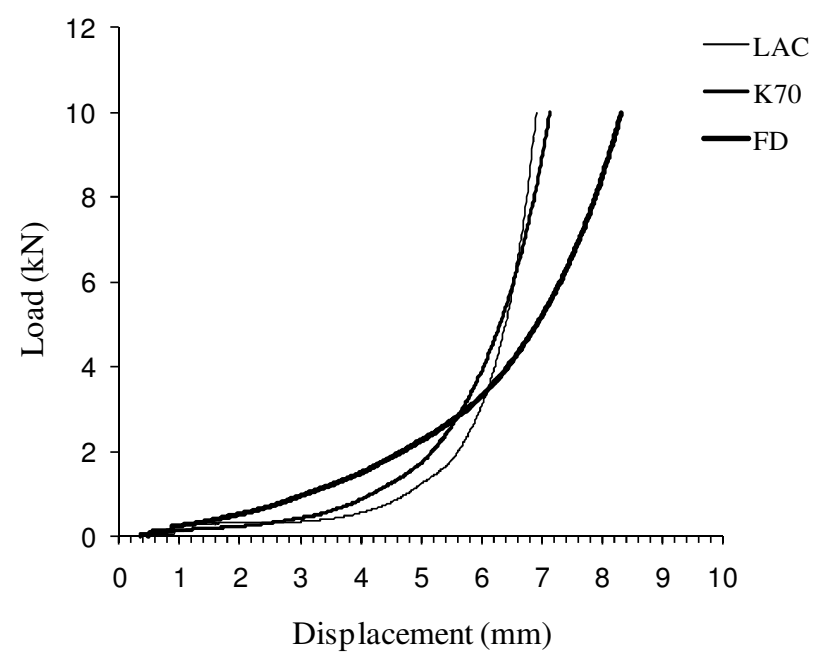

Fig. 3. Compaction profiles for the different mixtures at $10 \mathrm{kN}$ load.

\subsubsection{Extrusion profiles and spheronization}

The extrusion profiles for the wet masses of PL $(\mathrm{MCC}+\mathrm{IB}+\beta \mathrm{CD})$ and PL K70 (MCC + $\mathrm{IB} \beta C D$ K70) can be seen in Fig. 4. The profiles show a similar compaction phase but the steadystate phases are different. Although the energies of extrusion were similar $(1.13 \mathrm{KJ}$ and $1.21 \mathrm{KJ}$ for PL and PL K70, respectively), the tendencies of both curves were opposite: while the profile for PL kept increasing with extrusion the PL K70 profile decreased before the forced flow phase. It suggests that the two materials presented a different degree of lubrication, with the PL K70 being more lubricated than PL. This observation is coherent with the production of the masses: the same amount of water was added to both materials but the PL K70 was already exposed to water throughout the complex formation phase. It might be pointed out that the water required for extrusion might have promoted the formation of the complex in PL extrudates [17].

Spheronization of extrudates produced pellets with high sphericity and narrow size distribution: $67 \%$ and $66 \%$ for pellets within 1.0 and $1.4 \mathrm{~mm}$ diameter were collected for PL and PL K70 formulations, respectively. 


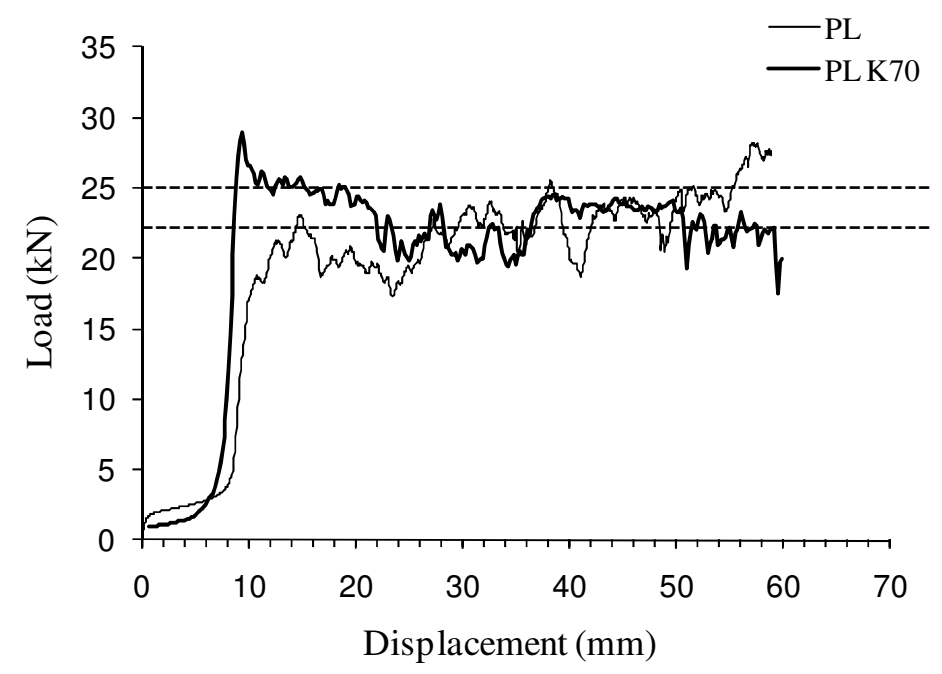

Fig. 4. Extrusion profiles of two wet mass formulations (PL and PL K70).

\subsubsection{Crushing and tensile strengths}

The tensile strength for both tablets and pellets formulas is shown in table 3 . The results for the processed formulations showed that IB $\beta$ CD FD tablets had a higher strength than others. The amorphous state and higher surface of the particles that characterized the IB $\beta$ CD FD mixture due to the freeze drying process, associated with high compaction force explains this result through the increase of the links between particles [24,29]. For the pellets this parameter showed differences between two formulations. The formulation containing the binary mixture previously obtained by the complexation method, produced pellets with greater resistance than the other formulation. The strength value for this dosage form is approximately 2 times higher. The kneading procedure promotes the formation of bounds which are intensified during the preparation of the wet mass.

\section{Table 3}

Tensile strengths and disintegration times for both tablets and pellets ${ }^{\text {a) }}$

\begin{tabular}{|c|c|c|c|}
\hline & \multicolumn{2}{|c|}{$\begin{array}{l}\text { Tensile Strength } \\
(\mathrm{MPa})\end{array}$} & \multirow{2}{*}{$\begin{array}{c}\text { Disintegration } \\
\text { (min) }\end{array}$} \\
\hline & Tablets & Pellets & \\
\hline IBLAC & $0.21 \pm 0.01$ & & 1.00 \\
\hline $\mathrm{IB} \beta \mathrm{CD} \mathrm{K} 70$ & $1.17 \pm 0.12$ & & 1.70 \\
\hline $\mathrm{IB} \beta \mathrm{CD}$ FD & $1.46 \pm 0.19$ & & $>60.00$ \\
\hline Com1 & $8.75 \pm 0.78$ & & 43.50 \\
\hline Com2 & b) & & 1.70 \\
\hline PL & & $0.050 \pm 0.08$ & c) \\
\hline PL K70 & & $0.103 \pm 0.05$ & c) \\
\hline
\end{tabular}




\subsubsection{Dissolution tests}

The dissolution profiles of the tablets and pellets carried out in dissolution medium $\mathrm{pH} 1.0$ can be seen in Fig. 5.
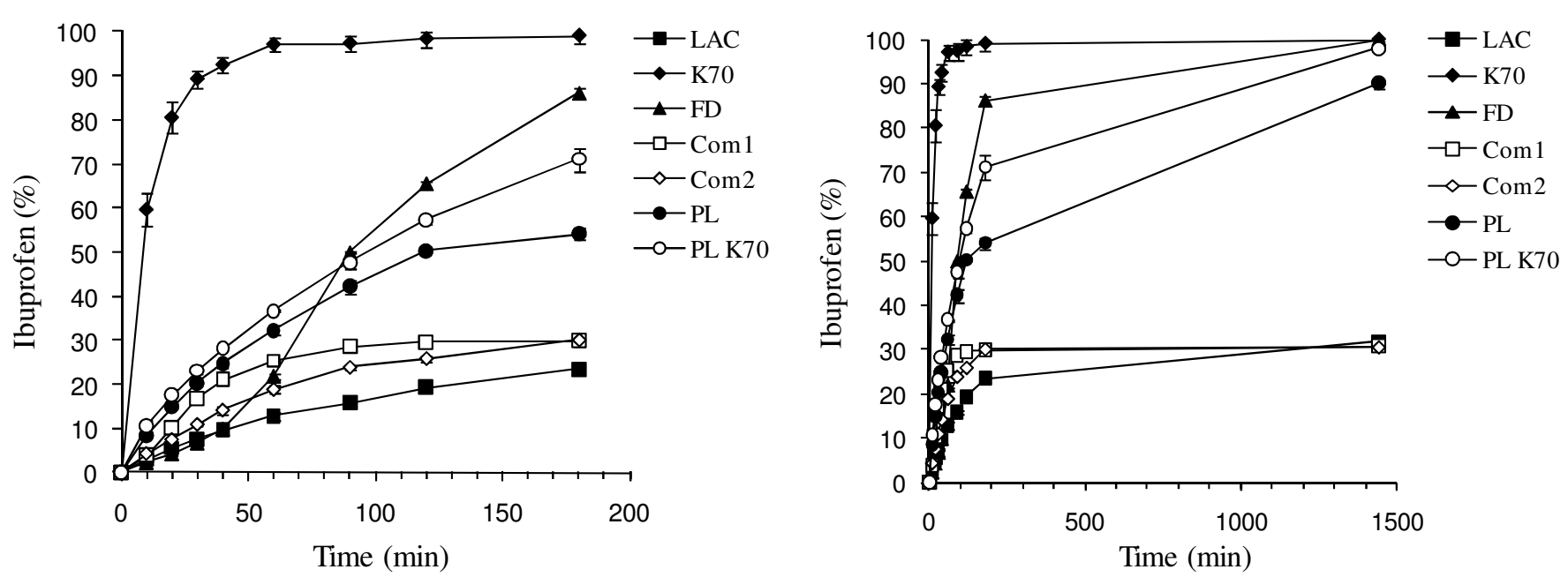

Fig. 5. Dissolution profiles of the tablets and pellets formulation at 180 and $1440 \mathrm{~min}$.

The dissolution profiles for the tablets formulations showed that IB under the form of inclusion complex (IB $\beta$ CD K70 and IB $\beta C D$ FD) presented higher solubility than IB not complexed (IBLAC). This fact confirms that the preparation methods used to produce the inclusion complex were efficient [5]. The difference between the two profiles in the first $180 \mathrm{~min}$ was due to the difficulty of the IB $\beta C D$ FD tablet disintegration (Table 3) for the reasons presented in 3.2.3. These tablets after $1 \mathrm{~h}$ presented only a slight disintegration. The particles' ${ }^{\prime}$ characteristics resulting from the drying method (freeze-drying) explains the releasing behavior of these tablets $[8,11,24,28]$. On the other hand, the quick disintegration of the IB $\beta C D$ K70 tablets exposes the particles of the inclusion complexes with the dissolution medium.

The amount of inclusion complex that exists in the two tablets formulations is almost the same as was presented in a previous work which concluded that the amount of water isn't an important parameter for the complexation yield [5]. At $1440 \mathrm{~min}$ both profiles reached 100\% IB which corroborated the study cited [5]. The reference tablet (IBLAC) showed a dissolution profile similar with two commercial formulations which didn't reach $100 \%$ of the drug released (plateau at $180 \mathrm{~min}<>$ approximately release of $30 \%$ ) due to the non existence of IB in the inclusion complex form. The IB corresponding to the intrinsic solubility released from these tablets lead to the saturation of the dissolution medium.

The dissolution profiles for the pellets formulations showed only small differences in between them. This observation confirmed that during the preparation of the wet mass, necessary for the extrusion procedure, the formation of the inclusion complex occurred with practically the same yield as obtained with the kneading method. The IB released from this dosage form corresponds to a prolonged release, as suspected due to the presence of MCC in the formulation and, is different to the release obtained with tablets $[8,17,30]$. The pellets did not disintegrate throughout the time of test, as expected $[17,18]$. 
As for the tablets, the IB released from the pellets reached almost $100 \%$ at $1440 \mathrm{~min}$. The IB released $(100 \%$ < $1440 \mathrm{~min})$ for both dosage forms containing inclusion complexes showed a greater yield in the complexation method that corroborates the results obtained in a previous work [5]. The results showed an increase in the IB solubility due to the formation of the inclusion complex when compared with references (IBLAC and commercials forms). The various dissolution parameters of the tablets and pellets are shown in Table 4.

The values presented for the ED parameter (Table 4) obtained from different tablets showed a larger difference between IB $\beta$ CD K70 and other tablet formulations (IB $\beta$ CD FD, reference and both commercial forms) at time $30 \mathrm{~min}$. The presence of IB as an inclusion complex is responsible for the difference between the reference formulation (IBLAC) and the commercial formulations (Com1 and Com2). The characteristics of the particles resulting from the method of preparation and the quick disintegration of the IB $\beta C D$ K70 tablet made the difference from the other formulation (IB $\beta C D$ FD) $[8,30,31]$. For the other times considered (60 and $180 \mathrm{~min}$ ) results have shown a more pronounced increase in the IB released from IB $\beta$ CD FD tablets. For the other tablets only small increases were observed and the release was not complete due to the absence of the complex, thus the IB released did saturate the dissolution medium.

\section{Table 4}

Dissolution parameters used ibuprofen tablets and pellets at $\mathrm{pH} 1.0$.

\begin{tabular}{|c|c|c|c|c|c|c|c|c|}
\hline & \multicolumn{3}{|c|}{$M_{t \min }(\%)^{a)}$} & \multicolumn{3}{|c|}{$D E(\%)$} & \multicolumn{2}{|c|}{$f_{2}(\%)$} \\
\hline & 30 & 60 & 180 & 30 & 60 & 180 & & \\
\hline IBLAC & $7.58 \pm 0.21$ & $12.84 \pm 0.86$ & $23.46 \pm 0.66$ & $\overline{4.04}$ & 7.20 & 14.84 & $(100.00)$ & \\
\hline $\mathrm{IB} \beta C D \mathrm{~K} 70$ & $89.26 \pm 1.85$ & $97.06 \pm 1.66$ & $99.09 \pm 1.66$ & 61.58 & 77.52 & 91.25 & 5.52 & \\
\hline $\mathrm{IB} \beta \mathrm{CD}$ FD & $6.71 \pm 0.66$ & $21.88 \pm 0.59$ & $86.10 \pm 0.97$ & 3.31 & 8.33 & 43.66 & 25.97 & \\
\hline Com1 & $16.84 \pm 0.74$ & $25.26 \pm 0.36$ & $29.85 \pm 0.21$ & 7.47 & 14.62 & 24.09 & 51.31 & \\
\hline Com2 & $10.94 \pm 0.20$ & $18.85 \pm 0.79$ & $30.03 \pm 1.30$ & 5.78 & 10.48 & 20.51 & 63.37 & \\
\hline PL & $20.29 \pm 0.08$ & $32.22 \pm 1.11$ & $54.05 \pm 1.28$ & 11.19 & 18.83 & 37.57 & 34.02 & $(100.00)$ \\
\hline PL K70 & $23.07 \pm 0.41$ & $36.66 \pm 0.30$ & $71.10 \pm 2.68$ & 13.26 & 21.70 & 44.39 & 27.97 & 56.80 \\
\hline
\end{tabular}

The similarity factor $\left(f_{2}\right)$ for the Com 1 and Com 2 formulation showed similarities with the IBLAC reference tablets with values above 50. Other tablets formulations didn't show to be similar due to the existence of the inclusion complexes.

Amounts of the IB released (\%) for 30,60 and $180 \mathrm{~min}$ for all the tablets formulations showed the same differences as discussed above. The release of IB increased, reaching $99.1 \%$ for IB $\beta$ CD K70 and $86.1 \%$ for IB $\beta$ CD FD formulation at time 180 min. After this time interval, the release of the IB for the reference and commercial tablets increased only slightly, resembling a plateau.

The dissolution parameters for the pellets formulations showed an increase in solubility of the IB which confirms the existence of the inclusion complexes. The similarity factor $\left(f_{2}\right)$ for both formulations (time $180 \mathrm{~min}$ ) showed similarity between them with values above 50 .

The amounts of drug released at the time 30,60 and 180 min were statistically evaluated for all formulations. The results for the tablets showed no statistically significant differences for IBLAC and IB $\beta C D$ FD formulations at time $30 \mathrm{~min}$ and Com 1 and Com 2 formulations at time 180 
min. The IB $\beta$ CD FD at time 180 min showed statistically significant differences compared with IBLAC and commercial formulations as previously explained. The IB $\beta$ CD K70 tablets showed at time 30 and 60 min large differences in the drug release comparatively with the others formulations. This is due to the easy disintegration of the tablet and consequent exposition of the inclusion complex to the dissolution medium. This rapid disintegration made the difference from IB $\beta C D$ FD tablets (because the existence of inclusion complex) with IBLAC, Com1 and Com2 tablets.

The pellets formulations showed differences with all other formulations because they are dosage forms of prolonged release. The increasing release of IB over time shows the existence of the inclusion complex.

\section{Conclusions}

This study showed that it is possible to produce tablets and pellets using powders mixtures containing inclusion complexes prepared by different complexation methods. The tablets were produced without additional excipients while in the pellets only MCC was used in the preparation of the wet mass. Throughout this study it was also possible to demonstrate that there is an increase of IB solubility (through dissolution profiles) from tablets and pellets in $\mathrm{pH}$ 1.0. The tablets release profiles were compared with a reference formulation and two commercial formulations showing large differences between them. The best formulations were IB $\beta$ CD K70 and IB $\beta$ CD FD due to the existence of the inclusion complex that allowed a $100 \%$ release of the drug. These dosage forms were produced without additional excipients. However, in the scale up transposition, small amounts of a lubricant, glidant and disintegrant will need to be added to facilitate the process (rotatory machine) and to improve the quality of the tablets.

The release profiles of the pellets formulations showed that it's not necessary to carry out the previous complexation process because the inclusion occurs, with practically the same yield, during the preparation of the wet mass. This observation is important for the industrial production. The profiles from both formulations showed a slow IB release (due MCC) when compared with tablets profiles, reaching almost $100 \%$ at a time lower than $1440 \mathrm{~min}$. This fact proves that the inclusion complex exists in great amount in pellets formulations.

In other formulation (reference formulation) an inclusion complex between IB and $\beta \mathrm{CD}$ do not exist and so the saturation of the medium with the drug occurred, which can be seen by the fact that they didn't reach the $100 \%$ drug release at final time of $1440 \mathrm{~min}$.

These new methodologies for the scale up allow significant cost savings on both processes (less energy and time consumption and fewer ingredients and processing steps involved in the tablets production and elimination of the previous complexation method for the pellets) with the consequent decrease in time and energy required.

\section{Acknowledgment}

J. Fernandes is acknowledged for their technical assistance on the preparation of this manuscript.

Declaration of interest

The authors report no conflicts of interest. 


\section{References}

[1] G.L. Amidon, H. Lennernas, V.P. Shah, J.R. Crison, A theorical basis for a biopharmaceutic drug classification: The correlation of in vitro drug product dissolution and in vivo bioavailability, Pharm. Res. 12 (1995) 413-420.

[2] J.M. Butler, J.B. Dressman, The Developability Classification System: Application of Biopharmaceutics Concepts to Formulation Development, J. Pharm. Sci. 99 (2010) 4940-4954.

[3] K.-H. Frömming, J. Szejtli, Cyclodextrins in Pharmacy. Kluwer Academic Publishers, Dordrecht, 1994.

[4] M.E. Brewster, T. Loftsson, Cyclodextrins as pharmaceutical solubilizers, Adv. Drug Deliv. Rev. 59 (2007) 645-666.

[5] P.J. Salústio, G. Feio, J.L. Figueirinhas, J.F. Pinto, H.M. Cabral Marques, The influence of the preparation methods on the inclusion of model drugs in a $\beta$-cyclodextrin cavity, Eur. J. Pharm. Biopharm. 71 (2009) 377-386.

[6] M. Charoenchaitrakool, F. Dehghani, N.R. Foster, Utilization of supercritical carbon dioxide for complex formation of ibuprofen and methyl- $\beta$-cyclodextrin. Int. J. Pharm. 239 (2002) 103-112.

[7] L.A. Miller, R.L. Carrier, I. Ahmed, Practical considerations in development of solid dosage forms that contain cyclodextrin, J. Pharm. Sci. 96 (2007) 1691-1707.

[8] M. Cirri, C. Rangoni, F. Maestrelli, G. Corti, P. Mura, Development of Fast-Dissolving Tablets of Flurbiprofen-Cyclodextrin Complexes, Drug Dev. Ind. Pharm. 31 (2005) 697-707.

[9] P. Mura, G.P. Bettinetti, A. Manderioli, M.T. Faucci, G. Bramanti, M. Sorrenti, Interactions of ketoprofen and ibuprofen with $\beta$-cyclodextrins in solution and in the solid state, Int. J. Pharm. 166 (1998) 189-203.

[10] T. Hladon, J. Pawlaczyk, B. Szafran...Stability of Ibuprofen in its Inclusion Complex with $\beta$ Cyclodextrin, J. Incl. Phenom. Macrocycl. Chem. 36 (2000) 1-8.

[11] K. Hussein, M. Türk, M.A. Wahln, Comparative Evaluation of Ibuprofen/ $\beta$-Cyclodextrin Complexes Obtained by Supercritical Carbon Dioxide and Other Conventional Methods, Pharm. Res. 24 (2007) 585-592.

[12] M.K. Ghorab, M.C. Adeyeye, High Shear Mixing Granulation of Ibuprofen and $\beta$ Cyclodextrin: Effects of Process Variables on Ibuprofen Dissolution, AAPS PharmSciTech. 8 (2007) E84.

[13] M. di Cagno, P.C. Stein, N. Skalko-Basnet, M. Brandl, A. Bauer-Brandl, Solubilization of ibuprofen with $\beta$-cyclodextrin derivatives: Energetic and structural studies, J. Pharm. Biomed. Anal. 55 (2011) 446-451.

[14] European Pharmacopoeia, Council of Europe, Strasbourg, France, 2008.

[15] R.L. Carr, Evaluating flow properties of solids, Chem. Eng. 18 (1965) 163-168.

[16] J.J. Sousa, A. Sousa, F. Podczeck, J.M. Newton, Factors influencing the physical characteristics of pellets obtained by extrusion-spheronization, Int. J. Pharm. 232 (2002) 91-106.

[17] A. Gainotti, R. Bettini, A. Gazzaniga, P. Colombo, F. Giordano, Drug- $\beta$-Cyclodextrin Containing Pellets Prepared with a High-Shear Mixer, Drug Dev. Ind. Pharm. 30 (2004) 1061-1068.

[18] E. Roblegg, S. Ulbing, S. Zeissmann, A. Zimmer, Development of lipophilic calcium stearate pellets using ibuprofen as model drug. Eur. J. Pharm. Biopharm. 75 (2010) 56-62.

[19] J.T. Fell, J.M. Newton, Assessment of compression characteristics of powders, J. Pharm. Sci. 60 (1971) 1428-1429.

[20] M. Salako, F. Podczeck, M. Newton, Investigations into deformability of and tensile strength of pellets, Int. J. Pharm. 168 (1998) 49-57.

[21] W. Li, B. Lu, F. Chen, F. Yang, Z. Wang, Host-guest complex of cypermethrin with $\beta$-cyclodextrin: A spectroscopy and theoretical investigation, J. Mol. Struct. 990 (2011) 244-252. 
[22] Guidance for Industry, Dissolution testing of immediate release solid oral dosage forms. U. S. Department of Health and Human Services. Food and Drug Administration. Center for Drug Evaluation and Research (CDER), (1997) [Online] Available at: www.fda.gov/cder/guidance/index.htm. Accessed on 10 March 2011.

[23] N.J. Staniforth, M.E. Aulton, Powder flow. In: Aulton ME, $3^{\text {th }}$ ed. Pharmaceutics, The Design and Manufacture of Medicines. London: Elsevier, 2007, pp. 168-179.

[24] D.Q.M. Craig, P.G. Royall, V.L. Kett, M.L. Hopton, The relevance of the amorphous state to pharmaceutical dosage forms: glassy drugs and freeze dried systems, Int. J. Pharm. 179 (1999) 179207.

[25] K. Schröder, K. Schmid, R. Löbenberg, Influence of Bulk and Tapped Density on the Determination of the Thermal Conductivity of Powders and Blends, AAPS PharmSciTech. 8 (2007) E78.

[26] P.J. Salústio, H.M. Cabral-Marques, P.C. Costa, J.F. Pinto, Comparison of ibuprofen release from minitablets and capsules containing ibuprofen: $\beta$-Cyclodextrin complex, Eur. J. Pharm. Biopharm. 78 (2011) 58-66.

[27] A. Mitrevej, N. Sinchaipanid, V. Junyaprasert, L. Warintornuwat, Effect of Grinding of $\beta$ Cyclodextrin and Glibenclamide on Tablet Properties. Part I. In Vitro, Drug Dev. Ind. Pharm. 22 (1996) 1237-1241.

[28] P. Mura, M.T. Faucci, P.L. Parrini, Effects of Grinding with Microcrystalline Cellulose and Cyclodextrins on the Ketoprofen Physicochemical Properties, Drug Dev. Ind. Pharm. 27 (2001) 119-128.

[29] K. Marshal, Compression and consolidation of powdered solids. In: Lieberman HA, Lachman L, Kanig JL, $3^{\text {th }}$ ed. The Theory and Practice of Industrial Pharmacy.Edited by Lea \& Febiger, Philadelphia, 1986, pp. 66-100.

[30] M.M. Ghorab, H.M. Abdel-Salam, M.A. El-Sayad, M.M. Mekhel, Tablet Formulation Containing Meloxicam and $\beta$-Cyclodextrin: Mechanical Characterization and Bioavailability Evaluation, AAPS PharmSciTech. 5 (2004) E59.

[31] K. Hussein, M. Türk, M.A. Wahl, Drug loading into $\beta$-cyclodextrin granules using a supercritical fluid process for improved drug dissolution, Eur. J. Pharm. Sci. 33 (2008) 306-312. 